\title{
The equivalent pier method for energy pile groups
}

\author{
A. F. ROTTA LORIA* and L. LALOUI†
}

\begin{abstract}
This study presents a method for estimating the average vertical displacement of energy pile groups subjected to thermal loads. The method consists of replacing any regular energy pile group with a single equivalent pier of the same length and an equivalent diameter. This equivalent pier is described by material properties that are a homogenisation of those of the piles and the surrounding soil and by a load-displacement relationship of a characteristic energy pile in the group. The load-displacement relationship of the equivalent pier differs from that of a single isolated energy pile because it is modified to account for the group effects. These effects include a greater vertical displacement of the piles subjected to loading in the group compared to the case in which they are isolated, thus involving a more pronounced average group displacement. Comparisons with results obtained through the interaction factor and finite-element methods prove that the proposed approach can accurately estimate the average vertical displacement of energy pile groups. This novel formulation of the equivalent pier method may be used at both preliminary and successive stages of the analysis and design of energy pile groups to assess expediently the thermally induced displacement response of such foundations.
\end{abstract}

KEYWORDS: deformation; design; elasticity; piles \& piling; plasticity; temperature effects

\section{INTRODUCTION}

The analysis and assessment of the displacement of pile groups subjected to loading are key steps for the design of such foundations. The reason for this is that the displacement of piles subjected to a load in a group is generally greater than the displacement that may be estimated for each of the piles in the group when dimensioned as a single isolated element for supporting the same load. This phenomenon arises because when the piles are located sufficiently close to each other, group effects induced by interactions between the displacement fields of the piles occur, and a different behaviour from that of a single isolated pile is involved. Group effects have been widely evidenced in conventional applications of piles subjected to mechanical loads when serving as structural supports for on- and offshore constructions (e.g. Whitaker, 1957; Sowers et al., 1961; Poulos, 1968; O’Neill, 1983). They have also been recently observed in innovative applications of energy piles subjected to both mechanical and thermal loads when serving as structural supports and geothermal heat exchangers for civil structures and infrastructures (e.g. Di Donna et al., 2016; Rotta Loria \& Laloui, 2016b).

To address the displacement response of conventional pile groups subjected to mechanical loads, consideration of a solid block composed of piles and the soil contained between them is a widely used approach in geotechnical engineering. The roots of this approach date back to over 40 years ago, when studies (Poulos, 1968; Poulos \& Davis, 1980; Butterfield \& Douglas, 1981) highlighted the effectiveness and suitability of replacing any pile group by a single equivalent pier that displaces an equal amount. Two types of

Manuscript received 8 June 2016; revised manuscript accepted 10 January 2017. Published online ahead of print 15 February 2017. Discussion on this paper closes on 1 January 2018, for further details see p. ii.

Published with permission by the ICE under the CC-BY license. (http://creativecommons.org/licenses/by/4.0/)

* Laboratory of Soil Mechanics (LMS), Swiss Federal Institute of Technology in Lausanne (EPFL), Lausanne, Switzerland (Orcid:0000-0001-6584-7526).

$\uparrow$ Laboratory of Soil Mechanics (LMS), Swiss Federal Institute of Technology in Lausanne (EPFL), Lausanne, Switzerland. approximations have generally been considered for this purpose: (a) a single pier of the same circumscribed plan area as the group with an equivalent length (Poulos, 1968) and (b) a single equivalent pier of the same length as the piles with an equivalent diameter (Poulos, 1993). This analysis approach, often termed the 'equivalent pier method', has been applied in various forms, including early formulations based on an elastic description of the pier-soil interaction that were applied through the boundary element method (Poulos \& Davis, 1980; Poulos, 1993) and successive formulations based on an elasto-plastic description of the piersoil interaction that were applied through the load-transfer method (Randolph \& Clancy, 1993; Randolph, 1994; Clancy \& Randolph, 1996; Horikoshi \& Randolph, 1998; Castelli \& Maugeri, 2002; Castelli \& Motta, 2003; McCabe \& Lehane, 2006; Sheil \& McCabe, 2014). The equivalent pier method is useful for a number of purposes, including the estimation of (a) the average vertical displacement of any relatively small pile group and $(b)$ the average and differential vertical displacement of any large foundation comprising a number of pile groups with the aid of other methods (e.g. the interaction factor method) to consider intergroup interaction. This method has been proven to provide results close to reality when applied to the analysis of closely spaced pile groups (Castelli \& Maugeri, 2002; Castelli \& Motta, 2003; McCabe \& Lehane, 2006; Sheil \& McCabe, 2014). Applying the equivalent pier method is generally suggested when the response of pile groups is predominantly elastic because the effects of the interactions among the piles that the method aims to capture are elastic. The method may still be applied for analysing the load-displacement behaviour of pile groups where non-linear soil response occurs around each pile. Based on these facts, European Standards (BS EN 1997 (BSI, 2004)) currently propose to analyse and design pile groups subjected to axial mechanical loads at both ultimate (collapse-related) and serviceability (deformation-related) limit states with this method.

Although characterised by different mechanisms and additional governing material parameters, the behaviour of energy pile groups subjected to thermal loads is considered to be characterised by a number of common physical factors related to the behaviour of conventional pile groups subjected 
to mechanical loads. These include the dependence of the capacity behaviour of any single energy pile in the group on the conditions at the pile-soil interface (e.g. friction piles) and pile base (e.g. end-bearing piles) (Rotta Loria et al., $2015 \mathrm{~b}$ ) and the dependence of the deformation behaviour of the group on the conditions in the soil away (i.e. far field) from the single energy piles composing it (Rotta Loria \& Laloui, 2016b). To address the displacement response of closely spaced energy pile groups subjected to thermal loads, considering the behaviour of a solid block constituted by the energy piles and the soil surrounding them may thus be suitable. This assessment appears attractive in view of the expedient capabilities of the equivalent pier approach for capturing the displacement response of conventional pile groups and the availability of only a simplified method for considering that of energy pile groups (Rotta Loria \& Laloui, 2016a).

Based on the above considerations, the goal of this study is to propose for the first time a formulation of the equivalent pier method for estimating the average vertical displacement of energy pile groups subjected to thermal loads by considering the mechanisms and variables governing the behaviour of such foundations.

In the following, the hypotheses and the mathematical formulation constituting the proposed method are first presented. The method is then applied to simulate the behaviour of groups of $2 \times 2,3 \times 3,4 \times 4$ and $5 \times 5$ energy piles and is validated based on a comparison with results obtained through the interaction factor and finite-element methods (Rotta Loria \& Laloui, 2016a). Finally, concluding remarks that can be drawn from this work are proposed.

\section{THE EQUIVALENT PIER METHOD FOR ENERGY PILE GROUPS}

\section{Hypotheses and considerations}

Reference is made in this study to energy piles and equivalent piers that are $(a)$ free to move vertically at their heads (i.e. no head restraint), (b) characterised by an infinitely flexible slab and $(c)$ free of superstructure mechanical loads. Aspect $(a)$ allows a safety side analysis against the effects of both monotonic and cyclic thermal loads (involving potentially irreversible effects at the pile-soil interface) to be made. Aspects $(b)$ and $(c)$ allow focusing for the purpose of the present study on the effects of the thermal loads applied to the energy piles rather than on those of the mechanical loads. Considering the presence of a slab connecting the energy piles and characterising the equivalent piers may indeed be feasible. In those cases, an effective approach may consist in assuming the slab as infinitely rigid. Poulos \& Davis (1974) and Selvadurai (1979) propose formulae for calculating the stiffness of slabs assumed as infinitely rigid elements. Poulos \& Davis (1980) remark, however, that the average settlement of a pile group characterised by an infinitely flexible slab is approximately equal to that of the same group with an infinitely rigid slab.

The energy piles are approximated as solid cylindrical prisms and form a regular geometry in plan view (e.g. square groups of energy piles). The equivalent piers are also considered to be solid cylindrical prisms. The proposed approach can also consider other cross-sectional shapes of the energy piles and the equivalent piers, as well as other arrangements of energy piles.

The materials constituting the energy pile, the equivalent pier and the soil domains are assumed to be isotropic, homogeneous and uniform. The material properties are considered to be insensitive to the considered temperature changes. The pipes inside the energy piles and the equivalent piers are not modelled. This choice involves considering the temperature field in these domains as that of the heat carrier fluid circulating inside the pipes in reality. The materials constituting the energy piles and the equivalent piers follow a linear thermo-elastic behaviour. The soil follows an elastoplastic behaviour, although the impact of the temperature changes observed in reality in this material on the response of the pile group is implicitly considered in the analyses.

The energy piles are considered to be socketed in a deep soil layer at the same initial temperature $T_{0}$ and are subjected to a temperature change, $\Delta T=T-T_{0}$, where $T$ is an actual temperature value. This temperature change is assumed to be (a) applied instantaneously and uniformly along the length of all of the piles in the group, $(b)$ constant with time and (c) equal for all the piles. The same temperature change is assumed to be applied to the equivalent piers. Considering situations in which different temperature changes or (equal or different) thermal powers would be applied to the energy piles may indeed be feasible.

The dominant mode of heat transfer in the soil is considered to be conduction. Moisture migration is negligible. The impact of groundwater advection is considered to be negligible. Thermal contact resistance between the energy piles and the soil is discounted. The variation of the thermal field at the ground surface as a consequence of a potential variation in the environmental conditions is assumed to be negligible. The aforementioned assumptions allow an expedient although simplified analytical resolution of the thermal problem characterising the single energy piles that may be needed when defining the homogenised material properties of the equivalent piers (see the later subsection entitled 'Homogenised material properties of the equivalent pier'). The temperature at the far fields from the pile group, namely, the (bottom) horizontal and vertical boundaries that may be considered to characterise the deep soil domain surrounding the piles, is assumed to remain constant with time and equal to $T_{\infty}=T_{0}$. The horizontal (top) boundary described by the soil surface is treated as adiabatic. Differences in the thermal field around the energy piles are expected for scenarios where the soil surface may be assumed to be adiabatic or characterised by a fixed constant temperature, with a consequent impact on the mechanical behaviour of these ground structures (Bodas Freitas et al., 2013). However, because the former condition appears to characterise real energy pile applications more closely than the latter (especially for piles located far from the external boundaries of large thermally insulated buildings), it is considered in this work.

The load-displacement behaviour of the equivalent piers is modelled using the one-dimensional load-transfer method proposed by Coyle \& Reese (1966). Only the axial displacements of the equivalent piers are considered. The radial displacements are neglected according to the considered one-dimensional approach. This choice appears to be justified based on the small values of radial displacements characterising single energy piles (Olgun et al., 2014) and the consequent limited impact of these displacements on the vertical displacement behaviour of the group. Horizontal stress decrease may occur at the shaft of single energy piles due to the application of cyclic thermo-mechanical loads involving non-linear soil response in this setting ( $\mathrm{Ng}$ et al., 2016). However, while a decrease of the displacement interaction among the piles may be expected because of this phenomenon, this effect would be counterbalanced by the increase in vertical displacement of the piles, resulting in an average group displacement that is almost unaffected. The self-weight of the material constituting the equivalent piers is neglected. The load-displacement relationship characterising the equivalent piers relies on a modification to account for the group effects of the relationships proposed by Knellwolf et al. (2011) and by Frank \& Zhao (1982). This modified load-transfer relationship has been 
implemented in software called Thermo-Pile for the analysis and design of energy piles. The load-displacement relationships used for characterising the single isolated energy piles and the equivalent piers are considered to be unaffected by any potential temperature effects. Although these effects were remarked for single energy piles in some situations (McCartney \& Rosenberg, 2011; Wang et al., 2011; Ng et al., 2015), they were not identified in others (Regueiro et al., 2012; Goode et al., 2014; Kramer \& Basu, 2014). These effects are considered to be negligible in the examples presented in this paper because they belong to the latter situations. Their consideration may improve the adherence of analyses to situations where the load-displacement relationship of single energy piles may be sensitive to temperature effects. Consideration of methods and relationships other than those used in this work to characterise the load-displacement behaviour of the energy piles and the equivalent piers may be possible.

In the following, compressive stresses, contractive strains and downward displacements (i.e. settlements) are considered to be positive.

\section{Geometry of the equivalent pier}

The key concept of the equivalent pier approach is that any regular pile group can be modelled as a single equivalent pier by considering the soil region in which the piles are embedded as a homogenised continuum (see Fig. 1). Such an equivalent pier is characterised by a length coincident with the average length of the piles and by an equivalent diameter that can be calculated as follows (Poulos, 1993).

For predominantly friction piles

$$
D_{\text {eq }} \approx 1.27 \sqrt{A_{\mathrm{g}}}
$$

For predominantly end-bearing piles

$$
D_{\text {eq }}=\frac{2}{\sqrt{\pi}} \sqrt{A_{\mathrm{g}}} \approx 1 \cdot 13 \sqrt{A_{\mathrm{g}}}
$$

where $A_{\mathrm{g}}$ is the plan area of the group. For any general configuration of piles, $A_{\mathrm{g}}$ can be determined as

$$
A_{\mathrm{g}}=A_{\mathrm{t}, \mathrm{EP}}+A_{\text {soil }}
$$

where $A_{\mathrm{t}, \mathrm{EP}}$ is the total cross-sectional area of the piles composing the group $\left(A_{\mathrm{t}, \mathrm{EP}}=n_{\mathrm{EP}} A_{\mathrm{EP}}\right.$ where $n_{\mathrm{EP}}$ is the number of piles in the group and $A_{\mathrm{EP}}$ is the cross-sectional area of a single pile) and $A_{\text {soil }}$ is the plan area of soil surrounding the piles delimited by the simplest polygon that better reproduces the shape of the pile group. For a square geometry of piles, $A_{\mathrm{g}}$ can be calculated as

$$
A_{\mathrm{g}}=\left[\left(\sqrt{n_{\mathrm{EP}}}-1\right) s+D\right]^{2}
$$

where $s$ is the centre-to-centre spacing between the piles and $D$ is the pile diameter.

Numerical analyses performed by the authors suggest that the choice of using equations (1a) and (1b) to determine $D_{\text {eq }}$ leads to differences of up to $5 \%$ between the estimated values of average vertical displacement. This result holds for both low and high magnitudes of thermal loads and mechanical loads imposed prior to the temperature changes to equivalent piers for common pile and soil strata stiffness and pile spacing.

Considering an equivalent pier of the same (average) length of the piles in the group and of an equivalent diameter appears to be preferable to considering an equivalent pier of the same circumscribed plan area as the group and an equivalent length. Reference to the same length of the piles allows consideration of the properties (e.g. thermal and mechanical) of the soil layers that may surround the pile group and govern its deformation and capacity behaviours.

Based on the considered approach, any pile group with a total cross-sectional area of piles

$$
A_{\mathrm{t}, \mathrm{EP}}=\pi \frac{D^{2}}{4} n_{\mathrm{EP}}
$$

is replaced by a single equivalent pier of cross-sectional area

$$
A_{\text {eq }}=\pi \frac{D_{\text {eq }}^{2}}{4}
$$

The shape of the pile group can be categorised by the 'aspect ratio' $(A R)$, which can be determined for a square geometry of piles in plan view as (Randolph \& Clancy, 1993)

$$
A R=\sqrt{\frac{n_{\mathrm{EP} S}}{L}}
$$

where $L$ is the (average) length of the piles. The equivalent pier approach has been proven to provide a representative
Actual pile group
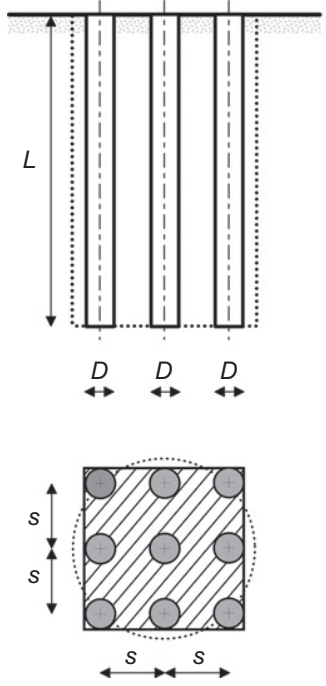

Equivalent pier
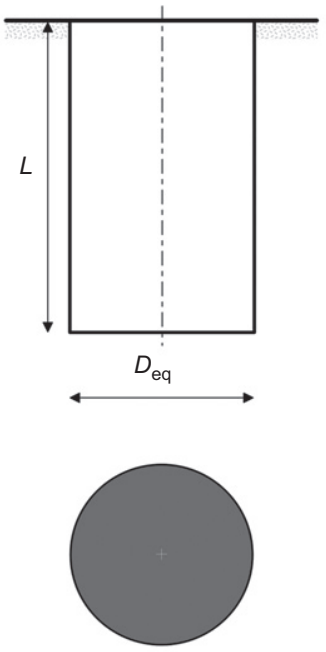

Plan area of soil, $A_{\text {soil }}$

Total cross-sectional area of piles, $A_{\mathrm{t}, \mathrm{EP}}$

Plan area of group, $A_{\mathrm{g}}$

Cross-sectional area of equivalent pier, $A_{\mathrm{eq}}$

Fig. 1. The modelling approach 
description of the behaviour (e.g. deformation and capacity) of conventional pile groups subjected to mechanical loads for values of $A R$ smaller than 4 and certainly less than 2 (Randolph, 1994). This approach has also been suggested to provide sufficiently accurate results for practical purposes (characterised by a $20 \%$ variation with those obtained using more rigorous approaches) for pile groups with a centre-to-centre pile spacing of up to five diameters (Poulos et al., 2002). The reason for this is that for larger $A R \mathrm{~s}$ $(A R>3-4)$ and wider pile spacing $(s>5 D)$, the pile group resembles a 'shallow' foundation more than a 'deep' foundation, so the hypothesis of a block behaviour of the group is no longer valid. Numerical analyses performed by the authors over a broad range of design conditions suggest that the considerations summarised above for conventional pile groups subjected to axial mechanical loads are also valid for energy pile groups subjected to thermal loads.

\section{Homogenised material properties of the equivalent pier}

There are two crucial dimensionless parameters that characterise the response of energy pile groups subjected to thermal and mechanical loads, assuming that the loads and all other material properties of the groups are the same (Rotta Loria \& Laloui, 2016a, 2016b): the pile-soil stiffness ratio, $\Lambda=E_{\mathrm{EP}} / G_{\text {soil }}$, where $E_{\mathrm{EP}}$ is the Young's modulus of the piles composing the group and $G_{\text {soil }}$ is the shear modulus of the soil $\left(G_{\text {soil }}=E_{\text {soil }} /\left[2\left(1+v_{\text {soil }}\right)\right]\right.$, where $E_{\text {soil }}$ is the Young's modulus of the soil and $v_{\text {soil }}$ is the Poisson ratio of the soil); and the soil-pile thermal expansion coefficient ratio, $X=\alpha_{\text {soil }} / \alpha_{\mathrm{EP}}$, where $\alpha_{\text {soil }}$ is the linear thermal expansion coefficient of the soil and $\alpha_{\mathrm{EP}}$ is the linear thermal expansion coefficient of the piles. The material properties involved in defining these two dimensionless ratios are considered for determining two key material properties in the characterisation of the response of the equivalent pier to thermal (and mechanical) loads: the equivalent Young's modulus, $E_{\mathrm{eq}}$, and the equivalent linear thermal expansion coefficient, $\alpha_{\text {eq }}$.

The equivalent pier can be characterised by an equivalent Young's modulus effectively homogenising that of the piles and of the soil embedded between them that can be calculated as the weighted average of the Young's modulus of these bodies as (Poulos, 1993)

$$
\begin{aligned}
E_{\mathrm{eq}} & =\frac{A_{\mathrm{t}, \mathrm{EP}} E_{\mathrm{EP}}+A_{\text {soil }} E_{\text {soil }}}{A_{\mathrm{t}, \mathrm{EP}}+A_{\text {soil }}} \\
& =E_{\mathrm{EP}} \frac{A_{\mathrm{t}, \mathrm{EP}}}{A_{\mathrm{g}}}+E_{\text {soil }}\left(1-\frac{A_{\mathrm{t}, \mathrm{EP}}}{A_{\mathrm{g}}}\right)
\end{aligned}
$$

This definition of the equivalent pier modulus accounts for the effect that the excess stiffness of the piles compared to that of the soil has on the deformability problem by considering superposition of the representative areas involved (see Fig. 2).

The equivalent pier can then be characterised by an equivalent linear thermal expansion coefficient that can be calculated as

$$
\begin{aligned}
\alpha_{\mathrm{eq}} & =\alpha_{\mathrm{EP}} \quad \text { for } X=\alpha_{\mathrm{soil}} / \alpha_{\mathrm{EP}} \leq 1 \\
\alpha_{\mathrm{eq}} & =\frac{A_{\mathrm{EP}} \alpha_{\mathrm{EP}}+A_{\mathrm{exc}} \alpha_{\mathrm{soil}} Y}{A_{\mathrm{EP}}+A_{\mathrm{exc}}} \\
& =\alpha_{\mathrm{EP}} \frac{A_{\mathrm{EP}}+A_{\mathrm{exc}} X Y}{A_{\mathrm{EP}}+A_{\mathrm{exc}}} \quad \text { for } X=\alpha_{\mathrm{soil}} / \alpha_{\mathrm{EP}}>1
\end{aligned}
$$

where $Y$ is a coefficient that relates the average temperature change in the soil to that in the energy piles within the plan

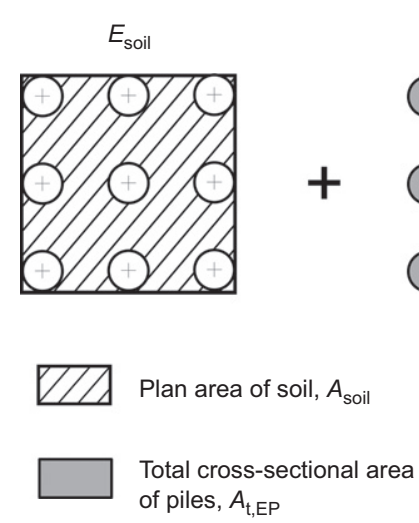

Fig. 2. Schematic representation for the calculation of the Young's modulus of the equivalent pier

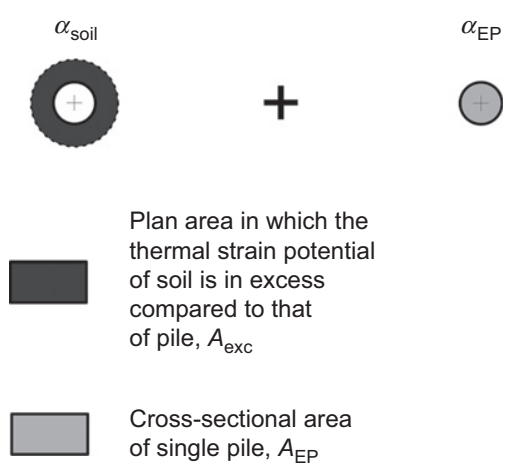

Fig. 3. Schematic representation for the calculation of the linear thermal expansion coefficient of the equivalent pier

area $A_{\text {exc }}$ in which the thermal strain potential of the soil is in excess compared to the thermal strain potential of the energy piles (see Fig. 3). The formulation of equation (8b), together with the associated assumptions and governing parameters, is presented below.

Equations (8a) and (8b) represent the key novelty that allows the application of the classical equivalent pier concept originally proposed for the displacement analysis of conventional pile groups subjected to only mechanical loads to energy pile groups that are also subjected to thermal loads. Equation (8a) expresses that when $X=\alpha_{\text {soil }} / \alpha_{\mathrm{EP}} \leq 1$, the deformation of the energy pile group may be interpreted and described by considering only the thermal expansion coefficient of the piles and the related thermally induced deformation because it governs that of the group. Equation (8b) highlights that when $X=\alpha_{\text {soil }} / \alpha_{\mathrm{EP}}>1$, the deformation of the energy pile group may be interpreted and described by considering also the thermal expansion coefficient of the soil surrounding the piles and the related thermally induced deformation because it profoundly characterises that of the group. In particular, the definition of equation (8b) is based on a similar concept to that characterising equation (7). Equation (8b) accounts for the impact of a linear thermal expansion coefficient of the soil in excess compared to that of the piles on the deformability problem by considering superposition of the representative areas involved. The phenomena described by equations ( $8 a$ ) and ( $8 b$ ) have been recently observed to characterise the deformation behaviour of energy pile groups subjected to thermal loads (Rotta Loria \& Laloui, 2016a, 2016b).

The fundamental assumption that allows the simple formulation of the equivalent linear thermal expansion 
coefficient expressed in equation (8b) to be obtained is that thermal interactions between the energy piles in any considered group are negligible.

This choice may represent an approximation of the real temperature field around the energy piles for long-term durations of applied thermal loads - especially in situations characterised by: $(a)$ soil deposits with high values of effective thermal conductivity; (b) small centre-to-centre spacing among the piles in the group; and $(c)$ soil deposits presenting groundwater flow (all of these aspects may facilitate the development of thermal interactions) - and may rarely characterise reality.

However, this choice is valuable because it involves determining the temperature field around the energy piles as if they were isolated heat sources, with a consequent effective determination of the parameters $Y$ and $A_{\text {exc }}$ needed in equation $(8 b)$.

The theoretical development of equation (8b) is as follows.

Context. In situations characterised by $X=\alpha_{\text {soil }} / \alpha_{\mathrm{EP}}>1$, interest lies in determining the extent of the plan area of soil $A_{\text {exc }}$ in which the thermal strain potential of this body is in excess compared to the thermal strain potential of the energy piles. There is a radial distance, $R_{\mathrm{exc}}$, in the soil for which this condition is satisfied and coincides with a temperature change, $\Delta T_{\text {soil }}$, that can be expressed with reference to free thermal expansion conditions as

$$
\begin{gathered}
\left|\varepsilon_{\text {th,free,soil }}\right|>\left|\varepsilon_{\text {th,free,EP }}\right| \rightarrow\left|-\alpha_{\text {soil }} \Delta T_{\text {soil }}\right|>\left|-\alpha_{\mathrm{EP}} \Delta T_{\mathrm{EP}}\right| \\
\rightarrow\left|\Delta T_{\text {soil }}\right|>\frac{\alpha_{\mathrm{EP}}}{\alpha_{\text {soil }}}\left|\Delta T_{\mathrm{EP}}\right| \Rightarrow \Delta T_{\text {soil }}=\frac{\Delta T_{\mathrm{EP}}}{X}
\end{gathered}
$$

where $\varepsilon_{\text {th,free,soil }}$ and $\varepsilon_{\text {th,free,EP }}$ are the thermal strains of the soil and the energy piles under free thermal expansion conditions and $\Delta T_{\mathrm{EP}}$ is the temperature change characterising (e.g. applied to) the energy piles. In normalised form, this temperature change is

$$
\frac{\Delta T_{\text {soil }}}{\Delta T_{\mathrm{EP}}}=\frac{1}{X}
$$

Determination of $\mathrm{A}_{\text {exc }}$. Knowledge of the evolution in space and with time of the temperature field around a single isolated energy pile enables $R_{\text {exc }}$ to be determined with reference to the normalised temperature change expressed in equation (9). The availability of $R_{\mathrm{exc}}$ allows the plan area of interest to be calculated as

$$
A_{\mathrm{exc}}=\pi \frac{D_{\mathrm{exc}}^{2}-D^{2}}{4}
$$

where $D_{\text {exc }}=2 R_{\text {exc }}$.

The hypothesis of no thermal interactions allows the temperature field around a single isolated energy pile to be expediently assessed through a number of analytical and semi-analytical solutions (e.g. Bergman et al., 2011). In this paper, the energy piles are considered to be a single isolated infinite heat source with a spherical gap (i.e. a continuous spherical body in one direction in space) subjected to a constant temperature change according to the conditions described in the earlier subsection entitled 'Hypotheses and considerations'. Consideration of the heat source as a continuous infinite spherical body eliminates the need for the two boundary conditions related to the top and bottom boundaries of the soil domain described under 'Hypotheses and considerations'. The evolution of the temperature field for radial distances, $r$, greater than the energy pile radius, $R$, with time, $t$, can consequently be determined semianalytically as (Bergman et al., 2011)

$$
T(r, t)=T_{\infty}+\left(T_{\mathrm{R}}-T_{\infty}\right) \frac{R}{r} \operatorname{erfc}\left(\frac{r-R}{\sqrt{4 t \alpha_{\mathrm{d}}}}\right)
$$

where $T_{\mathrm{R}}$ is the temperature at the energy pile radius (constant and uniform in the pile domain), erfc is the complementary 'Gaussian error function' and $\alpha_{\mathrm{d}}=\lambda /\left(\rho c_{\mathrm{p}}\right)$ is the soil thermal diffusivity (where $\lambda$ is the thermal conductivity, $\rho$ is the bulk density and $c_{\mathrm{p}}$ is the specific heat). The parameter $\alpha_{\mathrm{d}}$ may be calculated as an average value from the thermal diffusivity of different soil layers surrounding the pile length. This fact makes the present equivalent pier approach capable of approximately considering the thermal (and thus mechanical) behaviour of energy pile groups in layered soils.

Determination of Y. The plan area of soil $A_{\mathrm{exc}}$ is characterised by an average temperature change, $\Delta T_{\text {soil,ave, that can be }}$ determined analytically based on the results of equation (11). This average temperature change in the soil is related to the temperature change in the energy piles through a factor

$$
Y=\frac{\Delta T_{\text {soil,ave }}}{\Delta T_{\mathrm{EP}}} \quad \text { with } \frac{1}{X}<Y \leq 1
$$

Definition of $\alpha_{e q}$ (equation ( $\left.8 b\right)$ ). The average thermal strain potential of the soil under free thermal expansion conditions that is associated to $\Delta T_{\text {soil,ave }}$ in $A_{\text {exc }}$ is

$$
\varepsilon_{\text {th,free,soil,ave }}=-\alpha_{\text {soil }} \Delta T_{\text {soil,ave }}=-\alpha_{\text {soil }} \Delta T_{\mathrm{EP}} Y
$$

Therefore, the thermal strain potential under free thermal expansion conditions of any equivalent pier, considered as a system of $n_{\mathrm{EP}}$ energy piles of cross-sectional area $A_{\mathrm{EP}}$ and $n_{\mathrm{EP}}$ soil areas $A_{\text {exc }}$, is

$$
\begin{aligned}
\varepsilon_{\mathrm{th}, \mathrm{free}, \mathrm{eq}} & =\frac{n_{\mathrm{EP}} A_{\mathrm{EP}} \varepsilon_{\mathrm{th}, \mathrm{free}, \mathrm{EP}}+n_{\mathrm{EP}} A_{\mathrm{exc}} \varepsilon_{\text {th }, \text { free,soil,ave }}}{n_{\mathrm{EP}} A_{\mathrm{EP}}+n_{\mathrm{EP}} A_{\mathrm{exc}}} \\
& =\frac{A_{\mathrm{EP}} \varepsilon_{\mathrm{th}, \mathrm{free}, \mathrm{EP}}+A_{\mathrm{exc}} \varepsilon_{\mathrm{th}, \text { free,soil,ave }}}{A_{\mathrm{EP}}+A_{\mathrm{exc}}}
\end{aligned}
$$

Because the temperature change applied to the equivalent pier, $\Delta T_{\text {eq }}$, is assumed to be the same as that applied to the energy piles, from the above is found the formulation of the equivalent linear thermal expansion coefficient of the pier expressed in equation (8b).

$$
\begin{aligned}
-\alpha_{\mathrm{eq}} \Delta T_{\mathrm{eq}} & =-\alpha_{\mathrm{eq}} \Delta T_{\mathrm{EP}}=\frac{-\left(A_{\mathrm{EP}} \alpha_{\mathrm{EP}} \Delta T_{\mathrm{EP}}+A_{\mathrm{exc}} \alpha_{\mathrm{soil}} \Delta T_{\mathrm{EP}} Y\right)}{A_{\mathrm{EP}}+A_{\mathrm{exc}}} \\
\Rightarrow \alpha_{\mathrm{eq}} & =\frac{A_{\mathrm{EP}} \alpha_{\mathrm{EP}}+A_{\mathrm{exc}} \alpha_{\mathrm{soil}} Y}{A_{\mathrm{EP}}+A_{\mathrm{exc}}}
\end{aligned}
$$

Neglecting the thermal interactions among the energy piles involves disregarding the effect of the spacing among and position of the energy piles on the definition of $A_{\mathrm{exc}}$ and $Y$. A dependence of the thermal expansion coefficient of the equivalent pier on these features may effectively be present in reality.

Validation of semi-analytical solution (equation (11)). Figure 4 presents a comparison between the results obtained through the semi-analytical solution presented in equation (11) and a more rigorous thermal finite-element analysis 

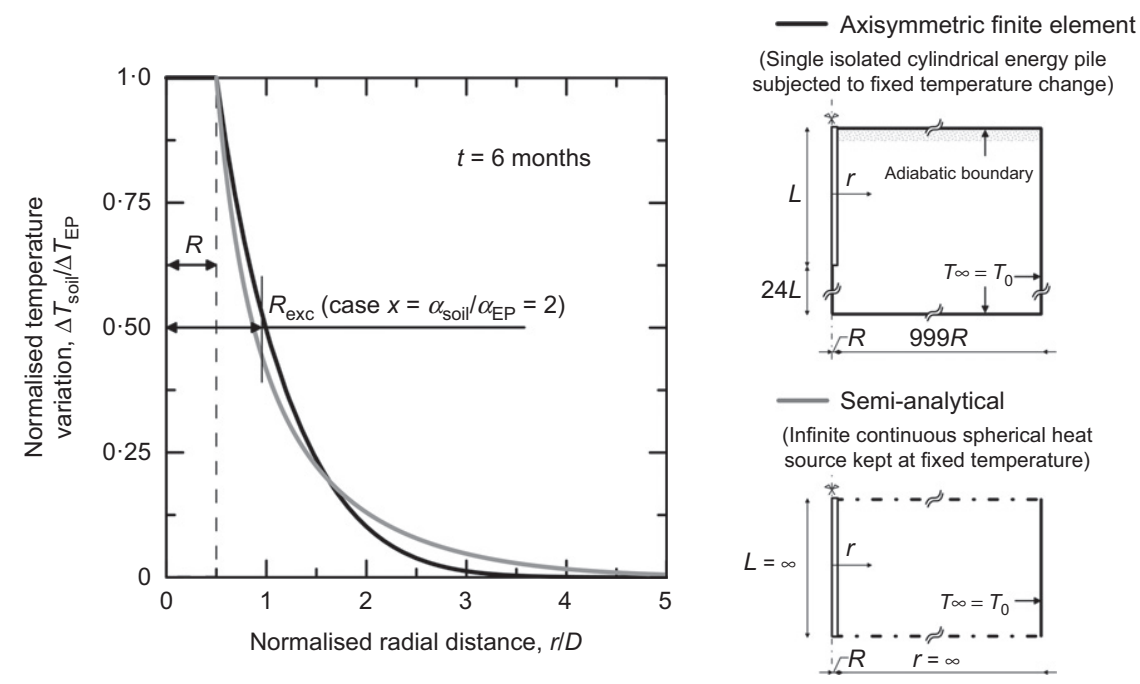

Fig. 4. Comparison between the evolutions of the normalised temperature variation with radial distance obtained using the semi-analytical solution and the finite-element method

performed with the software Comsol Multiphysics (COMSOL, 2014). The evolution of normalised temperature variation with radial distance from the axis of a single isolated energy pile subjected to a temperature change of $\Delta T=10^{\circ} \mathrm{C}$ for $t=6$ months (for the reference material properties referred to in the subsection entitled 'Material parameters') is presented. The radial distance $R_{\text {exc }}$ that can be used for calculating $A_{\mathrm{exc}}$ is highlighted for the case in which $X=\alpha_{\text {soil }} / \alpha_{\mathrm{EP}}=2$. Based on the comparison between the obtained results, it appears that the semi-analytical solution expressed in equation (11), among others, accurately captures the evolution of temperature change around a single isolated energy pile that can be obtained through more rigorous approaches of analysis such as the finite-element method. Therefore, equation (11) is suitable for calculating the parameters $A_{\text {exc }}$ and $Y$ needed in equation (8b).

\section{Load-displacement description of the equivalent pier}

An advantageous feature of the equivalent pier method is that the analysis of the displacement behaviour of the equivalent pier under loading can be based on solutions and/or methods proposed for the analysis of single isolated piles. However, these solutions must be modified for considering the group effects caused by the displacement interactions among the piles on the load-displacement response of the pile group. Such group effects involve a more pronounced average group displacement and thus a greater displacement of the equivalent pier.

To characterise the load-displacement relationship of the equivalent pier, reference is made in this study to a characteristic energy pile in the group that is subjected to the displacement interactions highlighted above. This characteristic energy pile can be considered to be representative of the displacement behaviour of most of the piles in the group. The characteristic energy pile may be considered as a side pile for small pile groups, whereas for large pile groups it may be considered as a pile located at an intermediate position between the centre and corner regions of the group. The reason for this definition is that centre and corner energy piles are characterised by the highest and lowest interactions, respectively, and are thus not representative of the behaviour of most of the piles in the group.

The load-transfer method considered in this work (Coyle \& Reese, 1966) for analysing the load-displacement behaviour of the equivalent pier relies on modelling this body as being composed of several rigid elements that are connected by springs representing the elastic pier stiffness. Each of these rigid elements is characterised at its side (i.e. a proportion of the shaft) by an elasto-plastic interaction with the soil. The element at the toe of the pier is characterised at its base by an elasto-plastic interaction with the soil. The element at the head of the pier is characterised at its top by a spring representing the elastic pier-structure interaction (the stiffness of this spring is considered to be null in the current application, following the assumptions made in the earlier subsection 'Hypotheses and considerations').

The elasto-plastic load-displacement relationships characterised by the features depicted in Figs 5(a) and 5(b) are considered in this work to govern the shaft and base resistance mobilisation for shaft and base displacement of the equivalent pier, respectively. The schematics of those relationships have been extended to energy pile groups from those that were proposed by Knellwolf et al. (2011) (see Figs 5(c) and 5(d)) for single isolated energy piles based on the ones presented by Frank \& Zhao (1982) for single isolated conventional piles. The shape of these functions is characterised by: (a) a first loading/unloading linear branch that describes the elastic response of the shaft/base of the equivalent pier/energy pile; (b) a next loading linear branch that refers to the inelastic response of the shaft/base of the equivalent pier/energy pile; $(c)$ an unloading linear branch that describes the elastic response of the shaft/base when unloading occurs from a stress state along the inelastic branch; and $(d)$ a final plateau that can be associated with the perfectly plastic response of the shaft/base of the equivalent pier/energy pile when the ultimate shaft/base resistance value is attained.

The first linear parts of the shaft and the base loaddisplacement (or load-transfer) functions of the equivalent pier cover shaft and base displacements of $w_{q_{\mathrm{seq}}} / 2$ and $w_{q_{\mathrm{beq}}} / 2$ until shaft and base resistances of $q_{\mathrm{s}, \mathrm{eq}} / 2$ and $q_{\mathrm{b}, \mathrm{eq}} / 2$ are mobilised, respectively. These values of shaft and base resistances are half of the ultimate shaft and base resistances of $q_{\mathrm{s} \text {,eq }}$ and $q_{\mathrm{b} \text {,eq }}$ of the equivalent pier, respectively. The same condition was considered by Frank \& Zhao (1982) for single isolated piles, with reference to shaft and base displacements of $w_{q_{\mathrm{s}}} / 2$ and $w_{q_{\mathrm{b}}} / 2$, intermediate shaft and base resistances of $q_{\mathrm{s}} / 2$ and $q_{\mathrm{b}} / 2$, and ultimate shaft and base resistances of $q_{\mathrm{s}}$ and $q_{\mathrm{b}}$, respectively. The slopes $K_{\mathrm{s} \text {,eq }}$ and $K_{\mathrm{b} \text {,eq }}$ of the loading/unloading elastic branches of the load-displacement functions of the equivalent pier represent the stiffness of the 


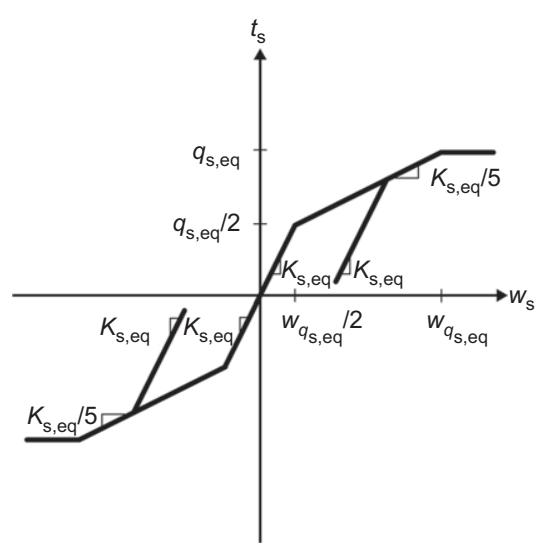

(a)

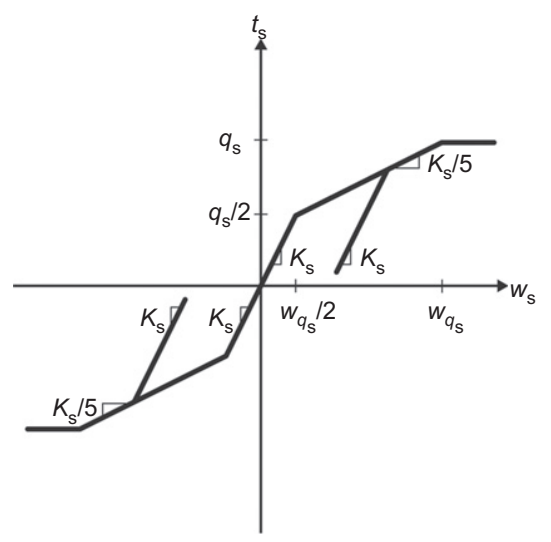

(c)

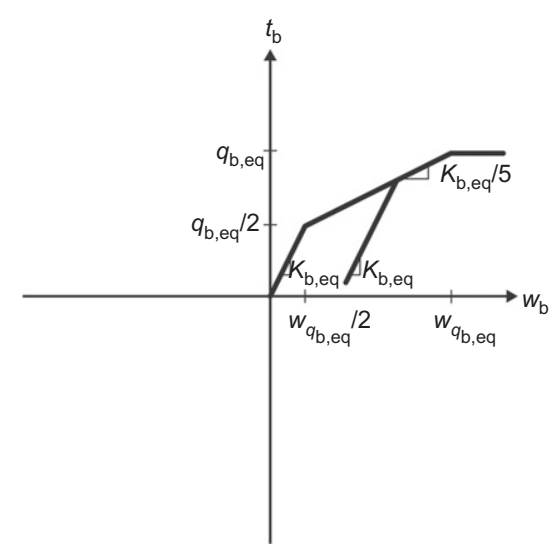

(b)

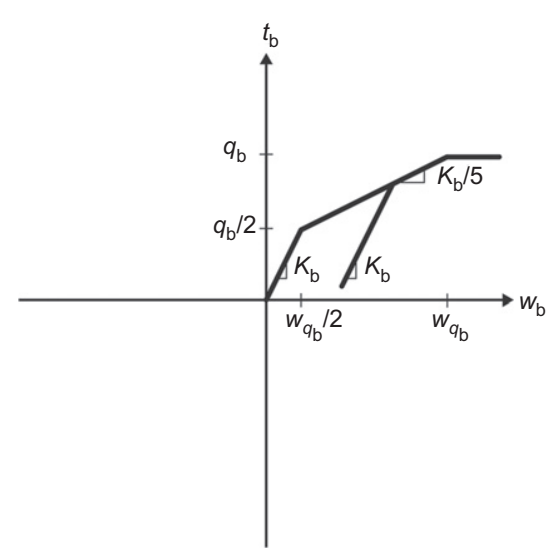

(d)

Fig. 5. Load-displacement relationships for: (a) the shaft and (b) the base of equivalent piers; and for (c) the shaft and (d) the base of single isolated energy piles

shaft and base springs that govern the elastic pier-soil interaction, respectively. The same physical meaning was considered by Frank \& Zhao (1982) for single isolated piles, with reference to the shaft and base stiffness $K_{\mathrm{s}}$ and $K_{\mathrm{b}}$, respectively. The slopes of the loading/unloading elastic branches of the shaft and base load-displacement functions of the equivalent pier are determined in this paper based on an extrapolation from the definitions presented by Frank et al. (1991) for single isolated piles and a correction through a novel parameter to account for the group effects as follows.

For coarse-grained soils

$$
\begin{aligned}
K_{\mathrm{s}, \mathrm{eq}} & =0.8 \frac{E_{\mathrm{M}}}{D} \zeta \\
K_{\mathrm{b}, \mathrm{eq}} & =4.8 \frac{E_{\mathrm{M}}}{D} \zeta
\end{aligned}
$$

For fine-grained soils

$$
\begin{aligned}
& K_{\mathrm{s}, \mathrm{eq}}=2 \frac{E_{\mathrm{M}}}{D} \zeta \\
& K_{\mathrm{b}, \text { eq }}=11 \frac{E_{\mathrm{M}}}{D} \zeta
\end{aligned}
$$

where $E_{\mathrm{M}}$ is the Menard pressuremeter modulus and $\zeta$ is a stiffness reduction factor.

The Menard pressuremeter modulus can be related to the Young's modulus of the soil according to different methods available in the literature (Clarke, 1994; Frank, 2009).
The stiffness reduction factor, $\zeta$, represents the key parameter to account for the group effects caused by the displacement interactions among the energy piles on the displacement response of the equivalent pier with reference to the behaviour of the characteristic energy pile. The definition of this parameter is based on a statement proposed by Randolph \& Clancy (1993) for which the interaction between the piles in any group can be broadly quantified through the ratio between the length of the piles and their centre-to-centre spacing, that is, $L / s$. This statement is corroborated by considerable evidence available in the literature for both conventional and energy pile groups (e.g. Poulos, 1968; Randolph \& Wroth, 1979; Rotta Loria \& Laloui, 2016a), which highlights that the interaction in any group increases with increasing pile length and decreases with increasing spacing between the piles. It thus appears rational to define a reduction factor for the stiffness of a single characteristic energy pile in any considered pile group that accounts for the interaction effects on the increase in displacement as

$$
\zeta=\frac{s}{L}
$$

The factor $\zeta$ varies between 0.04 and 0.5 in the practical pile applications for which the use of the equivalent pier method is suggested (see the earlier subsection entitled 'Geometry of the equivalent pier'). It physically represents a softening of the shaft and base load-transfer curves of single isolated piles for characterising those of the equivalent pier and addresses the difference in the displacement behaviour between single isolated energy piles and groups of 
energy piles under the same conditions. When this stiffness reduction factor attains the theoretical upper value of $\zeta=1$, equations (13) and (14) become the original relations proposed by Frank et al. (1991) for describing $K_{\mathrm{s}}$ and $K_{\mathrm{b}}$.

Various analyses were performed to define other appropriate formulations of $\zeta$. These analyses considered various combinations and/or selections of the parameters that may theoretically influence the deformation of pile groups (including, e.g. $D$ and $D_{\text {eq }}$ ), in linear and non-linear forms. However, the best results were found by using the proposed formulation. Although the definition of $\zeta$ does not include the pile diameter, this parameter is taken into account in the formulations of the shaft and base stiffness $K_{\mathrm{s}}$ and $K_{\mathrm{b}}$ proposed by Frank $\&$ Zhao (1982) that are multiplied by $\zeta$ to obtain the shaft and base stiffness of the equivalent pier $K_{\text {s,eq }}$ and $K_{\text {b,eq }}$. The definitions of the shaft and base stiffness of the equivalent pier thus account for three of the characteristics that are generally recognised to influence most the behaviour of pile groups, namely, the pile diameter, $D$, the pile spacing, $s$, and the pile length, $L$. Consideration of these characteristics in a linear form appears to be suitable for and in accordance with the linear nature of the load-displacement relationship employed to characterise the equivalent pier and single pile behaviours. Other formulations of the stiffness of the equivalent pier may indeed be considered and those presented in this paper may alternatively be calibrated with available experimental measurements.

The loading inelastic branches of the shaft and base loaddisplacement functions of the equivalent pier cover shaft and base displacements greater than $w_{q_{\mathrm{s}, \mathrm{eq}}} / 2$ and $w_{q_{\mathrm{b}, \mathrm{eq}}} / 2$ until the ultimate shaft and base resistances of $q_{\mathrm{s} \text {,eq }}$ and $q_{\mathrm{b}, \mathrm{eq}}$ are mobilised, respectively. The slopes of the inelastic branches of the equivalent pier related to the shaft and base are equal to $K_{\mathrm{s}, \mathrm{eq}} / 5$ and $K_{\mathrm{b} \text {,eq }} / 5$, respectively. The same condition was considered by Frank \& Zhao (1982) for single isolated piles with reference to $K_{\mathrm{s}} / 5$ and $K_{\mathrm{b}} / 5$.

The ultimate shaft and base resistances of the equivalent pier $q_{\mathrm{s} \text {,eq }}$ and $q_{\mathrm{b} \text {,eq }}$, respectively, may be determined considering $(a)$ the type of soil surrounding the piles, $(b)$ the method and order of installing the piles and $(c)$ the shaft and base

Table 1. Values of the aspect ratio $(A R)$ for the analysed energy pile groups

\begin{tabular}{l|c|c|c|c}
\hline \multirow{2}{*}{$s / D$} & \multicolumn{4}{|c}{ Values of $A R$} \\
\cline { 2 - 5 } & $\begin{array}{c}2 \times 2 \\
\text { energy pile } \\
\text { group }\end{array}$ & $\begin{array}{c}3 \times 3 \\
\text { energy pile } \\
\text { group }\end{array}$ & $\begin{array}{c}\text { 4 ergy pile } \\
\text { group }\end{array}$ & $\begin{array}{c}5 \times 5 \\
\text { energy pile } \\
\text { group }\end{array}$ \\
\hline 2 & 0.57 & 0.85 & 1.13 & 1.41 \\
2.5 & 0.63 & 0.95 & 1.26 & 1.58 \\
3 & 0.69 & 1.04 & 1.39 & 1.73 \\
5 & 0.89 & 1.34 & 1.79 & 2.24 \\
\hline
\end{tabular}

resistances of the single piles composing the group $q_{\mathrm{s}}$ and $q_{\mathrm{b}}$, respectively. Extensive summaries of methods that can be considered for this purpose are presented by Poulos \& Davis (1980) and Bowles (1988), among others.

\section{APPLICATION AND VALIDATION OF THE METHOD Analysed problems}

The reference problems analysed in this work comprise square groups of $2 \times 2,3 \times 3,4 \times 4$ and $5 \times 5$ semi-floating energy piles subjected to a temperature change of $\Delta T=10^{\circ} \mathrm{C}$ in soil deposits with different thermal expansion coefficients. An initial temperature in the energy pile and soil domains of $T_{0}=15^{\circ} \mathrm{C}$ is considered. The temperature change applied to the energy piles is imposed instantaneously and kept constant for $t=6$ months. Energy piles with a length of $L=25 \mathrm{~m}$ and a diameter of $D=1 \mathrm{~m}$ are analysed. Normalised centre-to-centre spacing between the energy piles of $s / D=2,2 \cdot 5,3$ and 5 , which represent the $A R \mathrm{~s}$ reported in Table 1 for the different energy pile groups analysed, are considered. Reference is made to the subsection entitled 'Hypotheses and considerations' for hypotheses and modelling considerations that may have been omitted.

The displacement behaviour of the energy pile groups described in this section was recently modelled by Rotta Loria \& Laloui (2016a) using the interaction factor method and more rigorous three-dimensional (3D) thermomechanical finite-element analyses. The results of these analyses are considered the references for comparison with the results obtained using the equivalent pier method proposed in this paper and the related validation. Detailed information on the features of the analyses performed through the interaction factor and finite-element methods by Rotta Loria \& Laloui (2016a) is presented in the referenced work.

\section{Material parameters}

Relevant parameters characterising the single energy piles composing the different groups and the surrounding soil are reported in Table 2. The properties of the energy piles are typical of reinforced concrete. The soil properties, for the nominal value of linear thermal expansion coefficient indicated, are characteristic of dry Nevada sand. These properties have been successfully employed by Rotta Loria et al. (2015a) to model the behaviour of energy piles in the considered soil with reference to physical observations (e.g. centrifuge tests of energy piles performed by Goode et al. (2014)). The ultimate shaft and base resistances of the single energy piles considered as isolated elements were determined by Rotta Loria \& Laloui (2016a). Useful equivalent pier-soil interaction parameters are summarised in Table 3 .

Relevant parameters characterising the equivalent piers reproducing the different energy pile groups analysed are reported in Tables 4-7. The ultimate shaft and base resistances of the equivalent piers are calculated by

Table 2. Material parameters for the energy piles and the soil

\begin{tabular}{|c|c|c|c|c|c|}
\hline \multicolumn{2}{|c|}{ Energy pile parameters } & \multicolumn{4}{|l|}{ Soil parameters } \\
\hline $\begin{array}{l}E_{\mathrm{EP}}: \mathrm{MPa} \\
v_{\mathrm{EP}} \\
\rho_{\mathrm{EP}}: \mathrm{kg} / \mathrm{m}^{3} \\
\alpha_{\mathrm{EP}}: 1 /{ }^{\circ} \mathrm{C} \\
\lambda_{\mathrm{EP}}: \mathrm{W} /\left(\mathrm{m}{ }^{\circ} \mathrm{C}\right) \\
c_{\mathrm{p}, \mathrm{EP}}: \mathrm{J} /\left(\mathrm{kg}{ }^{\circ} \mathrm{C}\right)\end{array}$ & $\begin{array}{r}30000 \\
0 \cdot 25 \\
2450 \\
1 \times 10^{-5} \\
1 \cdot 47 \\
854\end{array}$ & $\begin{array}{l}G_{\text {soil }}: \mathrm{MPa} \\
v_{\text {soil }}: \mathrm{kg} / \mathrm{m}^{3} \\
\rho_{\text {soil }}: \mathrm{k}: 1 / \mathrm{C}^{\circ} \\
\alpha_{\text {soil }}: \mathrm{W} /\left(\mathrm{m}{ }^{\circ} \mathrm{C}\right) \\
\lambda_{\text {soil }}: \mathrm{W} \\
c_{\mathrm{p}, \text { soil }}: \mathrm{J} /\left(\mathrm{kg}{ }^{\circ} \mathrm{C}\right)\end{array}$ & $\begin{array}{l}30 \\
0 \cdot 30 \\
1537 \\
0,0 \cdot 5 \times 10^{-5}, 1 \times 10^{-5 *}, 2 \times 10^{-5} \\
0 \cdot 25 \\
961\end{array}$ & $\begin{array}{l}K_{\mathrm{s}}: \mathrm{MPa} / \mathrm{m} \\
K_{\mathrm{b}}: \mathrm{MPa} / \mathrm{m} \\
q_{\mathrm{s}}: \mathrm{kPa} \\
q_{\mathrm{b}}: \mathrm{kPa}\end{array}$ & $\begin{array}{r}28 \\
168 \\
\\
38 \\
377\end{array}$ \\
\hline
\end{tabular}

*Value of linear thermal expansion coefficient characterising dry Nevada sand (Rotta Loria et al., 2015a). 
Table 3. Equivalent pier-soil interaction parameters

\begin{tabular}{l|c|c|c}
\hline$s / D$ & $\zeta$ & $K_{\mathrm{s}, \mathrm{eq}}: \mathrm{MPa} / \mathrm{m}$ & $K_{\mathrm{b}, \mathrm{eq}}: \mathrm{MPa} / \mathrm{m}$ \\
\hline 2 & $0 \cdot 08$ & $2 \cdot 24$ & $13 \cdot 44$ \\
$2 \cdot 5$ & $0 \cdot 10$ & $2 \cdot 80$ & $16 \cdot 80$ \\
3 & $0 \cdot 12$ & $3 \cdot 36$ & $20 \cdot 16$ \\
5 & $0 \cdot 20$ & $5 \cdot 60$ & $33 \cdot 60$ \\
\hline
\end{tabular}

Table 4. Parameters for the $2 \times 2$ energy pile groups

\begin{tabular}{l|r|r|r|c|c}
\hline \multicolumn{6}{l}{$2 \times 2$ energy pile groups } \\
\hline$s / D$ & $A_{\mathrm{g}}: \mathrm{m}^{2}$ & $D_{\text {eq }}: \mathrm{m}$ & $E_{\text {eq }}: \mathrm{MPa}$ & $q_{\mathrm{s}, \mathrm{eq}}: \mathrm{kPa}$ & $q_{\mathrm{b}, \mathrm{eq}}: \mathrm{kPa}$ \\
\hline 2 & 9 & $3 \cdot 81$ & 10523 & 40 & 104 \\
$2 \cdot 5$ & $12 \cdot 3$ & $4 \cdot 45$ & 7752 & 34 & 76 \\
3 & 16 & $5 \cdot 08$ & 5953 & 30 & 58 \\
5 & 36 & $7 \cdot 62$ & 2689 & 20 & 26 \\
\hline
\end{tabular}

Table 5. Parameters for the $3 \times 3$ energy pile groups

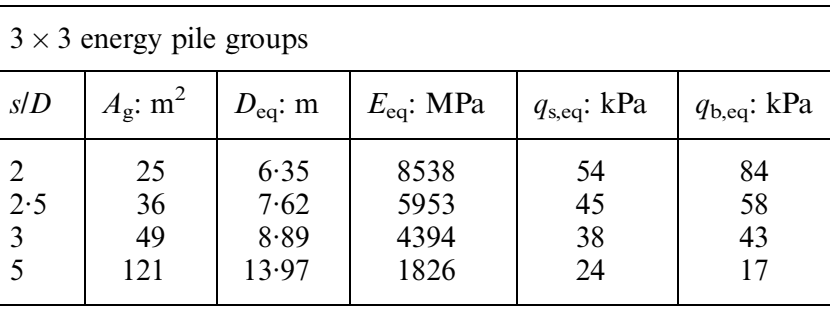

Table 6. Parameters for the $4 \times 4$ energy pile groups

\begin{tabular}{l|c|c|c|c|c}
\hline \multicolumn{6}{l}{$4 \times 4$ energy pile groups } \\
\hline$s / D$ & $A_{\mathrm{g}}: \mathrm{m}^{2}$ & $D_{\text {eq }}: \mathrm{m}$ & $E_{\text {eq }}: \mathrm{MPa}$ & $q_{\mathrm{s}, \mathrm{eq}}: \mathrm{kPa}$ & $q_{\mathrm{b}, \text { eq }}: \mathrm{kPa}$ \\
\hline 2 & 49 & $8 \cdot 89$ & 7752 & 68 & 76 \\
$2 \cdot 5$ & $72 \cdot 3$ & $10 \cdot 80$ & 5282 & 56 & 52 \\
3 & 100 & $12 \cdot 70$ & 3838 & 48 & 37 \\
5 & 256 & $20 \cdot 32$ & 1547 & 30 & 15 \\
\hline
\end{tabular}

Table 7. Parameters for the $5 \times 5$ energy pile groups

\begin{tabular}{l|c|c|c|c|c}
\hline \multicolumn{5}{l}{$5 \times 5$ energy pile groups } \\
\hline$s / D$ & $A_{\mathrm{gg}}: \mathrm{m}^{2}$ & $D_{\text {eq }}: \mathrm{m}$ & $E_{\text {eq }}: \mathrm{MPa}$ & $q_{\mathrm{s}, \mathrm{eq}}: \mathrm{kPa}$ & $q_{\mathrm{b}, \mathrm{eq}}: \mathrm{kPa}$ \\
\hline 2 & 81 & $11 \cdot 43$ & 7331 & 83 & 72 \\
$2 \cdot 5$ & 121 & $13 \cdot 97$ & 4934 & 68 & 48 \\
3 & 169 & $16 \cdot 51$ & 3554 & 57 & 35 \\
5 & 441 & $26 \cdot 67$ & 1410 & 36 & 13 \\
\hline
\end{tabular}

distributing the total shaft and base capacities of each group (calculated as the shaft and base capacities of the single isolated energy piles multiplied by the number of piles in the group for hypothesis) on the shaft and base area of the equivalent piers, respectively. This implies that

$$
q_{\mathrm{s}, \mathrm{eq}}=q_{\mathrm{s}} \frac{D}{D_{\mathrm{eq}}} n_{\mathrm{EP}}
$$

and

$$
q_{\mathrm{b}, \mathrm{eq}}=q_{\mathrm{b}} \frac{D^{2}}{D_{\mathrm{eq}}^{2}} n_{\mathrm{EP}}
$$

When possible, determination of the ultimate shaft and base resistances of the equivalent pier should be based on representative experimental evidence.

\section{Results}

Figure 6 presents a comparison between the results obtained through the application of the proposed equivalent pier method and the results obtained by Rotta Loria \& Laloui (2016a) using the interaction factor method and more rigorous $3 \mathrm{D}$ thermomechanical finite-element analyses to investigate the displacement behaviour of square groups of $2 \times 2,3 \times 3,4 \times 4$ and $5 \times 5$ energy piles. The evolution of the normalised average vertical head displacement with close values of the normalised centre-to-centre distance between energy piles that may be encountered in practice is presented. The vertical displacement is normalised with respect to the head displacement of a single energy pile under free thermal expansion conditions, $w_{\text {th,free }}=-\alpha_{\mathrm{EP}} \Delta T L / 2$. The equivalent pier and interaction factor methods consider the evolution of the normalised average vertical head displacement of the energy pile groups in soil deposits characterised by soil-pile thermal expansion coefficient ratios of $X=\alpha_{\mathrm{soil}} / \alpha_{\mathrm{EP}}=0$ and 2 . The curves predicted by the equivalent pier and interaction factor methods for $\alpha_{\mathrm{soil}} / \alpha_{\mathrm{EP}}=2$ are considered to be representative of the behaviour of energy pile groups for situations in which their deformation is governed by the thermally induced deformation of the soil (i.e. likely in all situations in which $\left.\alpha_{\text {soil }} / \alpha_{\mathrm{EP}}>1\right)$. The curves predicted by these methods for $\alpha_{\mathrm{soil}} / \alpha_{\mathrm{EP}}=0$ are considered to be representative of the behaviour of energy pile groups for all of the other situations in which their deformation is governed by the thermally induced deformation of the piles (i.e. situations in which $\alpha_{\text {soil }} / \alpha_{\mathrm{EP}} \leq 1$ ).

The results suggest a greater average vertical head displacement of the energy pile groups than the vertical head displacement characterising a single isolated energy pile subjected to the same temperature change under identical conditions. The displacement of the energy pile groups is also greater than that characterising a single energy pile under free thermal expansion conditions. This phenomenon arises because of the group effects and the related thermally induced interactions among the energy piles, and highlights the difference in the displacement behaviour of energy pile groups compared to single isolated energy piles.

The evolution of the displacement curves described by the results of both the finite-element and equivalent pier analyses is not monotonic, differently from that suggested by the interaction factor analysis. This phenomenon arises because the smaller the spacing between the piles is, the more damped are the individual deformations of the piles by the presence and the stiffness of these elements. Therefore, the average group displacement is not generally greater at closer pile spacing than at wider pile spacing and does not follow the approximately logarithmic evolution (decreasing with increasing pile spacing) that may be expected as a consequence of the displacement interaction relationship among piles. The evolution of the displacement curves described by the results of the interaction factor analysis is monotonic because of the limitations involved with this approach for describing the displacement behaviour of pile groups based on the displacement interaction between two piles in a pair and the displacement behaviour of a single isolated pile (Rotta Loria \& Laloui, 2016a).

The use of the equivalent pier method through the approaches described in the subsection entitled 'Homogenised material properties of the equivalent pier' captures the behaviour of energy pile groups. The estimates of the average vertical head displacement appear to be on the conservative side 


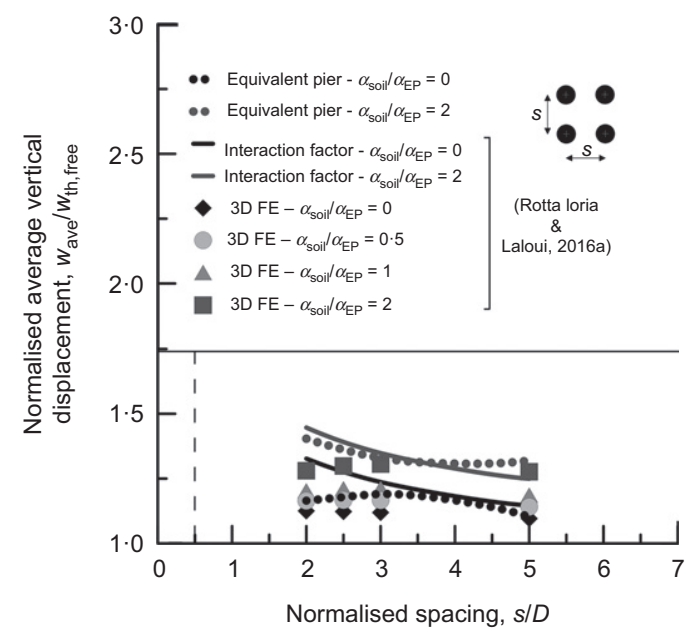

(a)

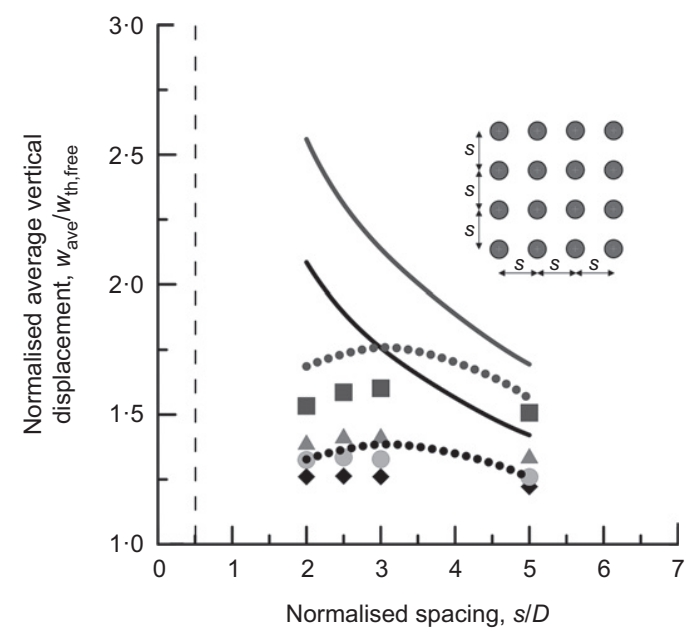

(c)

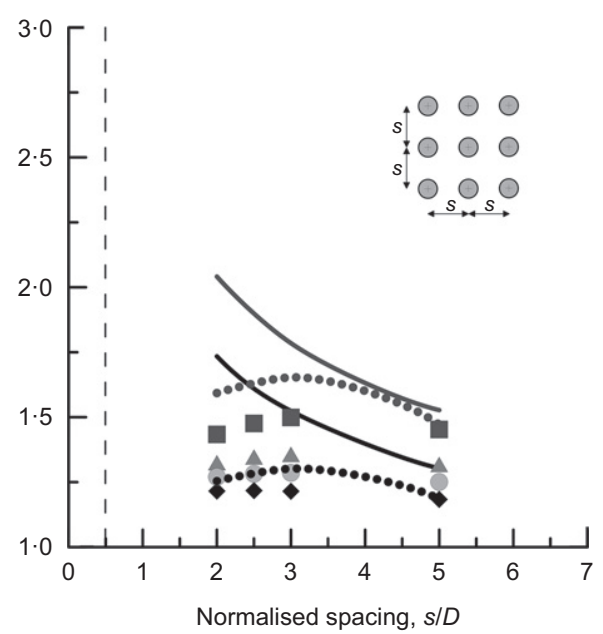

(b)

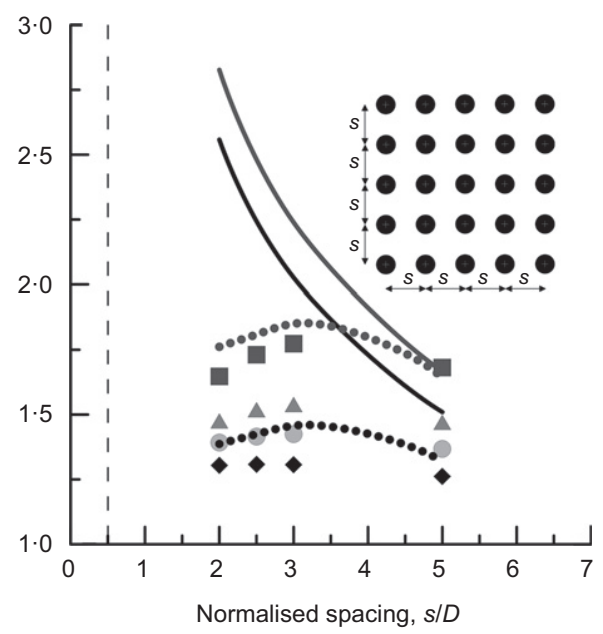

(d)

Fig. 6. Comparison between the results obtained using the proposed equivalent pier method, the interaction factor method and 3D thermomechanical finite-element analyses: (a) $2 \times 2$ pile group; (b) $3 \times 3$ pile group; (c) $4 \times 4$ pile group; (d) $5 \times 5$ pile group (FE, finite element)

in most of the considered cases, if reference is made to the more rigorous finite-element solutions. In cases in which an underestimation is noted, the difference is $(a)$ small compared to the values obtained through the finite-element solutions, (b) justified by the different features of the analyses and (c) considered to be acceptable for practical applications of the equivalent pier method. The percentage variation between the average vertical head displacement of the energy pile groups obtained through the equivalent pier analyses and the 3D finite-element analyses is in absolute value of up to $11 \%$. This percentage variation is of the same order of magnitude as that of $8 \%$ characterising the vertical head displacement of the single energy pile composing the analysed groups based on the results of one-dimensional load-transfer analyses and axisymmetric finite-element analyses. The above proves the comparable capability of the equivalent pier method of capturing the vertical head displacement of energy pile groups to that of the 3D finite-element method. The equivalent pier method is able to predict both the evolution and magnitude of normalised vertical head displacement with much greater accuracy compared to the interaction factor method for close spacing between the energy piles of up to five diameters. In particular, while the latter method has been suggested for spacing between the piles greater than five diameters (Rotta Loria \& Laloui, 2016a), the method proposed in this paper is suggested for the analysis of particularly closely spaced energy pile groups with pile spacing of up to five diameters. Despite being characterised by simplifying hypotheses and related shortcomings similar to most approximate methods, the equivalent pier and interaction factor methods are considered to be complementary approaches for investigating the behaviour of energy pile groups in a wide range of conditions. In particular, the equivalent pier and interaction factor methods are considered to be economically viable solutions for the analysis and design of energy pile groups. These methods may be preferred, especially in early design stages, to the more time-consuming, albeit more rigorous, finite-element method.

\section{CONCLUDING REMARKS}

The simplified yet rational method of analysis presented in this paper allows the average displacement behaviour of regular configurations of energy pile groups subjected to thermal loads to be estimated by considering the behaviour of a single equivalent pier.

The equivalent pier is a cylindrical solid with the same (average) length, $L$, of the energy piles composing any considered pile group and with an equivalent diameter, $D_{\mathrm{eq}}$. It is characterised by an equivalent Young's modulus, $E_{\text {eq }}$, and by an equivalent linear thermal expansion coefficient, $\alpha_{\text {eq }}$, that effectively homogenise those properties of the energy piles and soil. The definition through a dedicated approach presented in this paper of the equivalent linear thermal expansion coefficient of the pier represents the key novelty of the proposed equivalent pier method compared to classical equivalent pier formulations devoted to describing the behaviour 
of conventional pile groups subjected to (only) mechanical loads. The reason for this is that it allows the response of energy pile groups (also) subjected to thermal loads to be suitably considered depending on whether the behaviour of these groups is governed by the thermally induced deformation of the piles or of the surrounding soil. The displacement behaviour of the equivalent pier is modelled using the load-transfer method. Its load-displacement relationship is based on classical relationships proposed for the analysis of single isolated conventional and energy piles that are extrapolated and extended in this work to energy pile groups through the application of a stiffness reduction factor, $\zeta$. The factor $\zeta$ has been defined in this paper as a parameter that can be broadly considered to characterise displacement interactions in pile groups, namely, the ratio $s / L$ of the centre-to-centre spacing between the piles to their length. Application of this factor to the load-displacement functions defined for the shaft and base of single isolated piles accounts for the increase in the pile displacement in any pile group due to the group effects. The modified load-displacement relationships resulting from this approach, which are used to characterise the equivalent pier, may be associated with those of a characteristic pile in any considered pile group as this is representative of the displacement behaviour of most of the piles in the group. Although the approach presented in this work for modifying the considered load-displacement relationships of single isolated piles appears to be rational and leads to satisfying results, experimental evidence is needed for its further validation.

Based on the results presented in this study, the main conclusions that can be drawn from this work are as follows.

(a) Comparisons with results obtained through the simplified yet rational interaction factor method and the more rigorous $3 \mathrm{D}$ finite-element method prove that the theoretical approach described in this paper not only enables various trends in energy pile group behaviour to be studied but is also capable of accurately predicting the magnitude of the average vertical head displacement of energy pile groups.

(b) Despite being characterised by simplifying hypotheses and related shortcomings similar to most approximate methods, the proposed equivalent pier method is considered to be an economically viable and expedient solution for the analysis and design of energy pile groups. Its capabilities to (i) consider the material parameters governing the deformation (e.g. mechanically and/or thermally induced) and capacity of the energy piles and of any surrounding soil deposit, (ii) capture the potential non-linear behaviour of the soil surrounding energy pile groups and (iii) account for various soil layers surrounding the energy piles with properties that vary with depth make this method attractive compared to the more time-consuming, albeit more rigorous, finite-element method, especially in early stages of design.

(c) Application of this method is suggested for the analysis of energy pile groups characterised by an aspect ratio, $A R$, of less than 4 and normalised pile spacing of $s / D$ less than 5 ; for greater values of the considered parameters, the block-behaviour hypothesis of the pile group becomes less valid and the application of the method has a lower accuracy.

\section{ACKNOWLEDGEMENTS}

The help provided by Ms Pia Hartmann and Mr Benoit Cousin in exploring early aspects of the method proposed in this work is gratefully acknowledged. The financial support from the Swiss National Science Foundation (contract no. 160117, Division I-III) is appreciated.

\section{NOTATION}

$A$ cross-sectional area

$A_{\text {eq }}$ equivalent cross-sectional area

$A_{\text {exc }}$ plan area in which the thermal strain potential of soil is in excess compared to that of piles

$A_{\mathrm{g}}$ plan area of pile group

$A_{\text {soil }}$ plan area of soil delimiting the shape of the pile group

$A_{\mathrm{t}, \mathrm{EP}}$ total cross-sectional area of piles

$A R$ aspect ratio

$c_{\mathrm{p}} \quad$ specific heat

$\stackrel{\mathrm{p}}{D}$ diameter of pile

$D_{\text {eq }}$ equivalent diameter

$D_{\text {exc }}$ excess diameter

$E$ Young's modulus

$E_{\text {eq }}$ equivalent Young's modulus

$E_{\mathrm{M}} \quad$ Menard pressuremeter modulus

$G$ shear modulus

$K_{\mathrm{b}} \quad$ slope of loading/unloading elastic branch of base load-displacement function

$K_{\mathrm{s}}$ slope of loading/unloading elastic branch of shaft load-displacement function

$L \quad$ length of pile

$n_{\mathrm{EP}} \quad$ number of piles

$q_{\mathrm{b}} \quad$ ultimate base resistance

$q_{\mathrm{s}} \quad$ ultimate shaft resistance

$R$ radius of pile

$R_{\text {exc }}$ excess radius

$r$ radial coordinate

$s$ centre-to-centre distance between piles (spacing)

$T$ actual temperature

$T_{\text {ave }}$ average temperature

$T_{\mathrm{R}}$ actual temperature at pile radius

$T_{0}$ initial temperature

$T_{\infty} \quad$ temperature at far field

$t$ time

$w$ vertical displacement

$w_{\text {ave }}$ average vertical displacement

$w_{q_{\mathrm{b}}} / 2$ vertical base displacement mobilised for $q_{\mathrm{b}} / 2$

$w_{q_{\mathrm{s}}} / 2$ vertical shaft displacement mobilised for $q_{\mathrm{s}} / 2$

$w_{\text {th,free }}$ vertical displacement under free thermal expansion conditions

$X$ soil-pile thermal expansion coefficient ratio

$Y$ coefficient relating the average temperature change in the soil to that in the pile

$\alpha$ linear thermal expansion coefficient

$\alpha_{\mathrm{d}}$ thermal diffusivity

$\alpha_{\mathrm{eq}}$ equivalent linear thermal expansion coefficient

$\varepsilon_{\text {th,free }}$ strain under free thermal expansion conditions

$\varepsilon_{\text {th,free,ave }}$ average strain under free thermal expansion conditions

$\zeta$ stiffness reduction factor

$\Lambda$ pile-soil stiffness ratio

$\lambda$ thermal conductivity

$v$ Poisson's ratio

$\rho$ bulk density

\section{REFERENCES}

Bergman, T. L., Lavine, A. S., Incropera, F. P. \& DeWitt, D. P. (2011). Fundamentals of heat and mass transfer. Jefferson City, MO, USA: John Wiley \& Sons.

Bodas Freitas, T., Cruz Silva, F. \& Bourne-Webb, P. (2013). The response of energy foundations under thermo-mechanical loading. In Proceedings of 18th international conference on soil mechanics and geotechnical engineering, vol. 4, pp. 3347-3350. Paris, France: Comité Français de Mécanique des Sols et de Géotechnique.

Bowles, J. E. (1988). Foundation analysis and design. Singapore: McGraw-Hill.

BSI (2004). BS EN 1997: Eurocode 7: Geotechnical design. London, UK: BSI. 
Butterfield, R. \& Douglas, R. (1981). Flexibility coefficients for the design of piles and pile groups, Report 086017171X. London, UK: CIRIA.

Castelli, F. \& Maugeri, M. (2002). Simplified nonlinear analysis for settlement prediction of pile groups. J. Geotech. Geoenviron. Engng 128, No. 1, 76-84.

Castelli, F. \& Motta, E. (2003). Settlement prevision of piles under vertical load. Proc. Instn Civ. Engrs - Geotech. Engng 156, No. 4, $183-191$.

Clancy, P. \& Randolph, M. (1996). Simple design tools for piled raft foundations. Géotechnique 46, No. 2, 313-328, http://dx.doi.org/10.1680/geot.1996.46.2.313.

Clarke, B. G. (1994). Pressuremeters in geotechnical design. Boca Raton, FL, USA: CRC Press.

COMSOL (2014). COMSOL multiphysics version 4.4: user's guide and reference manual. Burlington, MA, USA: Comsol.

Coyle, H. M. \& Reese, L. C. (1966). Load transfer for axially loaded piles in clay. J. Soil Mech. Found. Div., ASCE 92, No. SM2, 1-26.

Di Donna, A., Rotta Loria, A. F. \& Laloui, L. (2016). Numerical study on the response of a group of energy piles under different combinations of thermo-mechanical loads. Comput. Geotech. 72, No. 1, 126-142.

Frank, R. (2009). Design of foundations in France with the use of Menard pressuremeter tests (MPM). Soil Mech. Found. Engng 46, No. 6, 219-231.

Frank, R. \& Zhao, S. (1982). Estimation par les paramètres pressiométriques de l'enfoncement sous charge axiale de pieux forés dans des sols fins. Bull. de Liaison des Laboratoire des Ponts et Chaussées 119, 17-24.

Frank, R., Kalteziotis, N., Bustamante, M., Christoulas, S. \& Zervogiannis, H. (1991). Evaluation of performance of two piles using pressuremeter method. J. Geotech. Engng 117, No. 5, 695-713.

Goode, J. III, Zhang, M. \& McCartney, J. S. (2014). Centrifuge modeling of energy foundations in sand In ICPMG2014 physical modelling in geotechnics (eds C. Gaudin and D. White), pp. 729-736. Boca Raton, FL, USA: CRC Press.

Horikoshi, K. \& Randolph, M. (1998). A contribution to optimum design of piled rafts. Géotechnique 48, No. 3, 301-317, http://dx.doi.org/10.1680/geot.1998.48.3.301.

Knellwolf, C., Peron, H. \& Laloui, L. (2011). Geotechnical analysis of heat exchanger piles. J. Geotech. Geoenviron. Engng 137, No. 10, 890-902.

Kramer, C. A. \& Basu, P. (2014). Performance of a model geothermal pile in sand. In ICPMG2014 - physical modelling in geotechnics (eds C. Gaudin and D. White), pp. 771-777. Boca Raton, FL, USA: CRC Press.

McCabe, B. \& Lehane, B. (2006). Behavior of axially loaded pile groups driven in clayey silt. J. Geotech. Geoenviron. Engng 132, No. 3, 401-410.

McCartney, J. S. \& Rosenberg, J. E. (2011). Impact of heat exchange on side shear in thermo-active foundations. In Proceedings of geo-frontiers: advances in geotechnical engineering (eds J. Han and D. E. Alzamora), GSP 211, pp. 488-498. Reston, VA, USA: American Society of Civil Engineers (ASCE).

Ng, C. W. W., Shi, C., Gunawan, A., Laloui, L. \& Liu, H. L. (2015). Centrifuge modelling of heating effects on energy pile performance in saturated sand. Can. Geotech. J. 52, No. 8, 1045-1057.

Ng, C. W. W., Ma, Q. \& Gunawan, A. (2016). Horizontal stress change of energy piles subjected to thermal cycles in sand. Comput. Geotech. 78, 54-61.

Olgun, C. G., Ozudogru, T. Y. \& Arson, C. (2014). Thermo-mechanical radial expansion of heat exchanger piles and possible effects on contact pressures at pile-soil interface. Géotechnique Lett. 4, No. 3, 170-178, http://dx.doi.org/10.1680/ geolett.14.00018.

O’Neill, M. W. (1983). Group action in offshore piles. In Proceedings of geotechnical practice in offshore engineering (ed. S. G. Wright), pp. 25-64. New York, NY, USA: American Society of Civil Engineers (ASCE).

Poulos, H. G. (1968). Analysis of the settlement of pile groups. Géotechnique 18, No. 4, 449-471, http://dx.doi.org/10. 1680/geot.1968.18.4.449.

Poulos, H. G. (1993). Settlement prediction for bored pile groups. In Proceedings of deep foundations on bored and auger piles (ed. W. F. Van Impe), pp. 103-117. Rotterdam, the Netherlands: Balkema.

Poulos, H. G. \& Davis, E. H. (1974). Elastic solutions for soil and rock mechanics. New York, NY, USA: John Wiley.

Poulos, H. G. \& Davis, E. H. (1980). Pile foundation analysis and design. New York, NY, USA: Wiley.

Poulos, H., Carter, J. \& Small, J. (2002). Foundations and retaining structures - research and practice. In Proceedings of the 15th international conference on soil mechanics and geotechnical engineering, vol. 4, pp. 2527-2606. Rotterdam, the Netherlands: Balkema.

Randolph, M. (1994). Design methods for pile groups and piled rafts. In Proceedings of the 13th international conference on soil mechanics and foundation engineering (XIII ICSMFE), pp. 61-82. Boca Raton, FL, USA: CRC Press.

Randolph, M. \& Clancy, P. (1993). Efficient design of piled rafts. In Deep foundations on bored and auger piles - bap II (ed. W. F. Van Impe), pp. 119-130. Rotterdam, the Netherlands: Balkema.

Randolph, M. F. \& Wroth, C. (1979). An analysis of the vertical deformation of pile groups. Géotechnique 29, No. 4, 423-439, http://dx.doi.org/10.1680/geot.1979.29.4.423.

Regueiro, R. A., Wang, W., Stewart, M. A. \& McCartney, J. S. (2012). Coupled thermo-poro-mechanical finite element analysis of an energy foundation centrifuge experiment in saturated silt. In Proceedings of geocongress 2012: State of the art and practice in geotechnical engineering (eds R. D. Hryciw, A. Athansopoulos-Zekkos and N. Yesiller), GSP 225, pp. 4406-4415. Reston, VA, USA: American Society of Civil Engineers (ASCE).

Rotta Loria, A. F. \& Laloui, L. (2016a). The interaction factor method for energy pile groups. Comput. Geotech. 80, 121-137.

Rotta Loria, A. F. \& Laloui, L. (2016b). Thermally induced group effects among energy piles. Géotechnique, http://dx.doi.org/ 10.1680/jgeot.16.P.039.

Rotta Loria, A. F., Di Donna, A. \& Laloui, L. (2015a). Numerical study on the suitability of centrifuge testing the thermal-induced mechanical behavior of energy piles. J. Geotech. Geoenviron. Engng 141, No. 10, 04015042.

Rotta Loria, A. F., Gunawan, A., Shi, C., Laloui, L. \& Ng, C. W. W. (2015b). Numerical modelling of energy piles in saturated sand subjected to thermo-mechanical loads. Geomech. Energy Environ. 1, No. 1, 1-15.

Selvadurai, A. P. (1979). Elastic analysis of soil-foundation interaction. Amsterdam, the Netherlands: Elsevier.

Sheil, B. B. \& McCabe, B. A. (2014). A finite element-based approach for predictions of rigid pile group stiffness efficiency in clays. Acta Geotechnica 9, No. 3, 469-484.

Sowers, G. F., Martin, C., Wilson, L. L. \& Fausold, M. (1961). The bearing capacity of friction pile groups in homogeneous clay from model studies. Proceedings of the 5th international conference on soil mechanics and foundation engineering, Paris, France, pp. 155-159.

Wang, B., Bouazza, A. \& Haberfield, C. (2011). Preliminary observations from laboratory scale model geothermal pile subjected to thermal-mechanical loading. In Proceedings of geo-frontiers 2011: advances in geotechnical engineering (eds J. Han and D. E. Alzamora), GSP 211, pp. 430-439. Reston, VA, USA: American Society of Civil Engineers (ASCE).

Whitaker, T. (1957). Experiments with model piles in groups. Géotechnique 7, No. 4, 147-167, http://dx.doi.org/10.1680/ geot.1957.7.4.147. 